\title{
Analysis on the Publicity and Education Effect of Urban Community Middle-Aged and Elderly People Nutrition and Dietary
}

\author{
Xiaoyuan Xing $^{1, a}$ Wei Tian ${ }^{1, b}$ Shuhong Zhang ${ }^{1, c}{ }^{\text {Yanxia Zhang }}{ }^{1, d}$ \\ Hongxia Cai ${ }^{1, e}$ Shuxin Liu ${ }^{1, f}$ \\ ${ }^{1}$ Langfang Health Vocational College, Langfang, Hebei, China, 065001
}

Keywords: Community Residents; Middle-Aged and Elderly People; Dietary Nutrition; Publicity and Education

\begin{abstract}
Objective: After surveying the nutrition situation of over 45-year-old middle-aged and elderly residents in 4 residential quarters of Langfang City, our experimental group formulates a scientific plan for health education, publicity and education on the dietary nutrition of the residents of the community to provide more effective health education service for community residents, improve and enhance the community residents' diet health to improve the quality of life. The purposes are making the nutrition and diet knowledge deeply rooted in the hearts of the people, making the majority of community residents through the publicity and education activities to obtain nutrition expertise and providing theoretical guidance for a healthy diet. Methods: The questionnaire was designed according to the purpose of the research, the investigation team was trained, the field investigation was carried out, and the propaganda and education were carried out by means of propaganda and manual. SPSS data analysis and processing are used. Outcome: In the process of carrying out publicity and education, because of the influence of city residents on nutrition and health education by the nutrition and diet knowledge, ranging from the level of community residents culture and living habits of many factors, makes the special research results appear more significant medical statistical significance. Especially in this part of the cognition of community residents to nutrition and diet, the effect of education is more prominent; but the residents to change the attitude and behavior on the cognitive basis, the dietary habits and cognitive level of the different effect are not obvious. Conclusion: The city community residents' diet and health education should be combined with local residents' situation and needs actually, and carried out with various forms of activities to popularize the nutrition and chronic non infectious disease knowledge.
\end{abstract}

\section{Introduction}

As we all know, China has entered an aging society, a variety of chronic non-communicable diseases is leading to the elderly quality of life and life shortages of the main factors. Many chronic non-communicable diseases have a very close relationship with people's daily dietary nutrition. Preventive and health care organizations have been carrying out advocacy work aimed at "preventing and reducing nutrition-related diseases". Community residents health diet, letter, line of the status quo is an important indicator of the level of community health services. In this study, through the education and publicity activities of nutrition and dietary knowledge of middle-aged and elderly population in some communities in Langfang, according to the survey results of the questionnaire before and after the dietary nutrition education and education, we discuss and discuss the nutrition and dietary education work in the community. To find out the main problems, to develop a scientific health education model for community residents to provide more effective health diet guidance services to improve and enhance the health of the elderly.

\section{Materials and Methods}

Research Objects. In Hebei Province, Langfang City, four residential areas randomly selected over 45 years of age in 110 cases of the elderly. It includes 47 males and 63 females. Their ages are from 
45 to 80 years, with an average age of $65.6 \pm 9.6$ years.

Methods. Investigator training. Before the implementation of the community publicity and education activities, I study the team after a month of training and learning. In the way of publicity, attention to issues, the issuance of small gifts, communication and other aspects of a comprehensive training, and focus on the subjectivity of the questionnaire, the authenticity of the principles and significance.

Design of the questionnaire. According to the data to be obtained from this study, we have not changed from the aspects of cognition, attitude and behavior of the residents of the community before and after the education of nutrition and dietary knowledge, and whether there was any statistics before and after the same questionnaire meaning of the analysis.

Survey quality control. In this experiment, we mainly used the same questionnaire to investigate the same questionnaire before and after the experiment, and analyzed the results of the two surveys, thus excluding the characteristics of the population (age, gender, occupation, nationality, education level) and so on, so that the choice of subjects to meet the experimental design. While the effective questionnaire recovery rate of $95 \%$, the loss rate is also controlled within the expected range. So this experiment has the authenticity, reliability.

Investigation method. A questionnaire survey was conducted on 110 randomly selected middle-aged and elderly people on July 1, 2015. During the period of July 10, 2015, the experimental group was administered once a month by dietitians to diet and nutrition of the residents System introduction, and the dissemination of promotional items (nutrition manual, dietary guidance leaflets, etc.). At the end of the experiment (June 2016), the same person was surveyed again with the same questionnaire and the results were surveyed. The survey includes seven major nutrients, "Chinese residents' dietary pagoda", diet and hypertension, diet and diabetes, the physiological characteristics of the elderly population and access to nutrition and dietary knowledge and so on. Nutrition and dietary publicity before and after the questionnaire survey of the indicators, the effective questionnaire recovery rate of more than $95 \%$.

Statistical methods. Statistical analysis software SPSS10.0 was used to analyze the results of two surveys, $\mathrm{P}<0.05$ was statistically significant.

\section{Results}

The Awareness, Attitude, Behavior Comparison before and after the Publicity and Education of Nutrition and Dietary Knowledge. Nursing and Nutrition Knowledge Before and after the publicity and education and 110 questionnaires were conducted among the middle - aged and elderly people who participated in the experiment. The contents were related to dietary and nutritional knowledge, dietary and nutritional attitudes, and dietary and nutritional control. Through the nutrition and dietary knowledge of the publicity and education, residents of the understanding of food nutrition have been greatly improved in the relationship between nutrition and chronic diseases have a deeper understanding. Table 1, Table II and Table III below.

Table 1 Analysis of cognition of dietary and nutritional knowledge $(\mathrm{N}=110)$.

\begin{tabular}{|c|c|c|c|c|c|}
\hline \multirow{2}{*}{ Investigate Subject } & \multicolumn{2}{|c|}{$\begin{array}{l}\text { Before the publicity and } \\
\text { education is known }\end{array}$} & \multicolumn{2}{|c|}{$\begin{array}{l}\text { After the publicity and } \\
\text { education of awareness }\end{array}$} & \multirow{2}{*}{$\mathrm{P}$} \\
\hline & $\begin{array}{c}\text { The number of } \\
\text { people }\end{array}$ & $\%$ & $\begin{array}{c}\text { The number of } \\
\text { people }\end{array}$ & $\%$ & \\
\hline $\begin{array}{l}\text { Three major production } \\
\text { nutrients }\end{array}$ & 8 & 7.3 & 96 & 87.3 & 0.00 \\
\hline High quality protein & 48 & 43.6 & 101 & 91.2 & 0.00 \\
\hline Protein complementary & 26 & 23.6 & 98 & 89.1 & 0.00 \\
\hline Vitamin source & 68 & 61.8 & 92 & 83.6 & 0.0001 \\
\hline The source of calcium & 66 & 60.0 & 95 & 86.4 & 0.00 \\
\hline The source of dietary fiber & 45 & 40.9 & 104 & 94.5 & 0.00 \\
\hline $\begin{array}{l}\text { The understanding of the } \\
\text { meal pagoda }\end{array}$ & 55 & 50.0 & 97 & 88.2 & 0.00 \\
\hline
\end{tabular}


Table 2 The attitude of the elderly at the diet and nutrition before and after the publicity and education $(n=110)$

\begin{tabular}{|c|c|c|c|c|c|}
\hline \multirow[t]{2}{*}{ content } & \multicolumn{2}{|c|}{$\begin{array}{l}\text { There is a clear attitude } \\
\text { before the publicity and } \\
\text { education }\end{array}$} & \multicolumn{2}{|c|}{$\begin{array}{c}\text { There is a clear attitude } \\
\text { after the publicity and } \\
\text { education }\end{array}$} & \multirow[t]{2}{*}{$\mathrm{P}$} \\
\hline & $\begin{array}{l}\text { The number } \\
\text { of people }\end{array}$ & $\%$ & $\begin{array}{l}\text { The number } \\
\text { of people }\end{array}$ & $\%$ & \\
\hline $\begin{array}{l}\text { Food is related to blood } \\
\text { pressure }\end{array}$ & 96 & 87.3 & 104 & 94.5 & $0.073^{*}$ \\
\hline $\begin{array}{l}\text { Food is related to blood } \\
\text { sugar }\end{array}$ & 98 & 89.1 & 105 & 95.45 & $0.076^{*}$ \\
\hline $\begin{array}{l}\text { Physiological } \\
\text { characteristics of middle } \\
\text { - aged and old people }\end{array}$ & 64 & 58.2 & 106 & 96.4 & 0.00 \\
\hline Food and health & 95 & 86.4 & 103 & 93.64 & $0.075^{*}$ \\
\hline $\begin{array}{l}\begin{array}{l}\text { Reasonable diet is } \\
\text { healthy }\end{array} \\
\end{array}$ & 98 & 89.1 & 105 & 95.45 & $0.076^{*}$ \\
\hline
\end{tabular}

* Indicates its $\mathrm{P}>0.05$.

Table 3 Survey of the elderly in the diet and nutrition before and after the publicity and education under the guidance of a reasonable regulation (behavior) $(n=110)$

\begin{tabular}{|c|c|c|c|c|c|}
\hline \multirow{2}{*}{ content } & \multicolumn{2}{|c|}{$\begin{array}{l}\text { Before the publicity and } \\
\text { education of a } \\
\text { reasonable sense of } \\
\text { regulation of food }\end{array}$} & \multicolumn{2}{|c|}{$\begin{array}{l}\text { After the publicity and } \\
\text { education of a reasonable } \\
\text { sense of regulation of food }\end{array}$} & \multirow[t]{2}{*}{$\mathrm{P}$} \\
\hline & $\begin{array}{c}\text { The } \\
\text { number of } \\
\text { people }\end{array}$ & $\%$ & $\begin{array}{c}\text { The number of } \\
\text { people }\end{array}$ & $\%$ & \\
\hline Staple food & 78 & 70.9 & 98 & 89.1 & 0.0001 \\
\hline Livestock & 56 & 50.9 & 95 & 86.4 & 0.00 \\
\hline Fruits and vegetables & 43 & 39.1 & 103 & 93.6 & 0.00 \\
\hline Milk & 44 & 40.0 & 97 & 88.2 & 0.00 \\
\hline Eggs & 54 & 49.1 & 101 & 91.8 & 0.00 \\
\hline Beans & 77 & 70.0 & 99 & 90.0 & 0.0001 \\
\hline Edible oils & 39 & 35.5 & 45 & 40.9 & $0.32 *$ \\
\hline Salt & 52 & 47.3 & 57 & 51.8 & $0.50 *$ \\
\hline liqueur & 58 & 52.7 & 89 & 80.9 & 0.00 \\
\hline Sugar & 26 & 23.6 & 85 & 77.3 & 0.00 \\
\hline
\end{tabular}

* Indicates its $\mathrm{P}>0.05$.

Results and Discussion. Results. Through the experimental data analysis, before and after the publicity and education of the elderly on the understanding of dietary and nutritional knowledge of the survey $(n=110)$, the results shown in Table 1 . Table 1 of the survey items, it is mainly in the elderly community residents to understand the nutritional knowledge of the situation. Which the awareness of the three major production capacity of nutrients in the publicity before the education of only 8 people in our group propaganda investigators to implement publicity and education activities after the increase to 96 people, the reason may be too much specialized production capacity of nutrients, for many The crowd is very strange, but in the second questionnaire, the awareness rate greatly increased, indicating that our publicity and education activities with real effectiveness; the second and third high-quality protein and protein complementary publicity and education before and after the change is also great, one of which is the application of the terminology of nutrition, the second reason may be the people of the protein knowledge is unclear, in the investigation process, when asked about people's understanding of the protein, a considerable 
number of people cannot tell, and even some people think protein only exists in the animal food, "eat Han fill what" concept is deep, after the nutrition and dietary publicity manual release, community publicity column to explain a year later, from the second questionnaire can be seen in the crowd. Second, the fifth group of experimental groups trying to understand the community residents of calcium and vitamin awareness, from the two papers awareness rate, in the absence of publicity and education activities before the majority of the masses of calcium and vitamin awareness to far more than the first three of the cognitive, which may be related to television advertising and other publicity; the sixth survey is on dietary fiber, dietary fiber nutrition sector as the seventh largest nutrient, its powerful, but in the process of education, the greater the understanding of the residents more like to eat coarse grains, but the source of dietary fiber is limited to a small amount of coarse grains cereals, nutrition and dietary learning manual learning to understand, people's vision is also open the last one of the questionnaires was about the scientific and rational distribution of a person's daily diet, and the awareness rate of the meal was not low, it has reached $50 \%$ to explore the reasons, because some public service advertising promotion, such as the bus on the outer wall of the posters, the hospital's LED display on the nutritional knowledge of the rolling play, but not everyone is serious to watch these nutritional knowledge, and the experimental team to these nutritional knowledge in the form of nutrition manual issued to the residents in the hands of the same time to do a lot of publicity in the district, to re-questionnaires, the residents of its awareness rate to reach $88.2 \%$ has a significant effect. Based on the above findings, the P value of each survey is less than 0.01 , with significant statistical significance.

In Table 2, the main statistics of the elderly in the experimental group before and after publicity and education, its nutritional diet and health relationship is clear attitude. The first and the second of the question were related to the relationship between food and blood pressure and blood glucose. The visit was found that the incidence of hypertension and diabetes was increasing year by year in community residents, and the clinical doctor's guidance, most of the hypertension and diabetes patients have a preliminary understanding of dietary structure, so the first and second statistical results $\mathrm{P}>0.05$, no statistically significant. The third is about community residents on the physiological characteristics of the elderly cognitive attitude is clear. Publicity before education to know the physiological characteristics of the elderly is different from the number of other groups of 64 , after my experimental group of publicity and education, the number rose to $106, \mathrm{P}$ value is far less than 0.05, a significant statistical significance. The fourth is food and health related, the fifth is a reasonable diet healthy. These two $\mathrm{P}$ values are greater than 0.05 , no medical significance. It can be seen that community residents are well aware of the health and well-being of meals and healthy meals.

In Table 3, the main statistics of the elderly in the experimental group before and after publicity and education, its behavior under the guidance of diet and nutrition is clear. In the questionnaire of the three questions, the experimental group mainly from the staple food, poultry, fruits and vegetables, milk, eggs, beans, edible oil, salt, wine, sugar and other aspects of a reasonable diet behavior survey The from the statistical data of Table 3 can be seen, in addition to edible oil and salt of the two statistical results $\mathrm{P}>0.05$, no medical significance, other items of the survey, the $\mathrm{P}$ value of less than 0.05 , with significant medical significance the after visiting the analysis found that although most of the residents have learned that edible oil and salt too much on the human body is not beneficial, but many years of living habits, not to say that can be changed immediately to change, so for the consumption of oil and salt the amount of restrictions should also continue to emphasize the publicity, and urge residents per person daily consumption of edible oil shall not exceed $25 \mathrm{~g} / \mathrm{d}$, salt intake of not more than $6 \mathrm{~g} / \mathrm{d}$, and long-term adherence can be effective Prevent the incidence of chronic non-communicable diseases such as hypertension, obesity and so on.

Discussion. With the development of Chinese economy, the improvement of residents' living, the dietary structure of the dining table is also quietly changing, the formation of heavy salt, heavy oil, heavy sugar and other living habits, so that many chronic non-communicable diseases known as the elderly potential killer in human life. This is inextricably linked to the lack of nutritional awareness, the poor self-control ability and the lack of knowledge of preventive health care in many 
community residents.

The residents of the community after a monthly diet and nutrition education, from the experimental population of the questionnaire can be analyzed in the nutritional knowledge of knowledge, attitude and behavior are significantly improved, such as dietary fiber, "Chinese residents dietary pagoda ", the relationship between food and chronic diseases and other understanding, before and after the experiment found that there are different degrees of difference. Through the survey found that a year after the community residents on the table meal greatly improved, further explained through the publicity and education distance with the community residents to promote their acceptance of preventive health care strategies, methods and other effective, which is also in line with middle-aged friends yearning for scientific knowledge, the desire to change the quality of life with knowledge. For example, in the survey found that many elderly people will be milk for drinking yogurt, and the proportion of drinking higher than before the experiment, and as we advocate every day, "a vegetable, a bean, an egg plus some meat," this meal concept, every day the intake of vegetables to the majority of people up to $500 \mathrm{~g}$, and then, community residents on the understanding of dietary fiber compared with the experiment before, with a more significant increase, but the intake of lipid food and salt in the majority of the family table there is no significant improvement, which indicates that the dining table on the pursuit of food taste dominated, so in the future we need to increase the lipid and salt nutrients and minerals into the human body, they play the physiological role and important to the human body organ impact, so that people understand their more thorough.

Through this experiment, we found that dietary and nutritional education activities is a long-term relay work, in the next period of a long period of time without interruption to the masses of all ages popular nutrition knowledge, so that people in the long-term contact learning process fully understand the dietary structure, and choose a reasonable dietary structure for food selection, cooking and ingestion, thereby reducing the development of nutritional diseases and chronic non-communicable diseases. In the future work, we will be through various forms of public health intervention and other measures (such as outside the bus paste "Chinese residents dietary pagoda"), so that publicity and education can be seen in order to achieve the promotion of individual and group health, prevention of disease and improve life , quality of life. The whole nation is united and fought side by side, and the victory of the second health revolution will be achieved.

\section{Acknowledgements}

Fund Project: This article is 2016 Langfang City Science and Technology Research and Development Program (the first batch) Self-Financing Project, the title: Research on Langfang city above 45-year-old residents' dietary nutrition and health status, the project number: 2016013043.

\section{References}

[1] Zeng Guo, Jiang Yan, Zhao Xiaoyan, etc. Urban community signed residents' nutrition knowledge - letter - line and guidance needs of the survey [J]. China Health Education, 2007, 23 (4): 251-254.

[2] Li Yinglin. Rural residents in Shaanxi Province health knowledge behavior and demand survey [J]. China Health Education, 2009, 25 (2): 143-145.

[3] Li Hui.Chinese community in two communities of chronic diseases and nutrition knowledge, attitude, behavior survey[J]. China Primary Health Care, 2008, 22 (11): 75-77.

[4] Wu Qinmin. Huai'an elderly diet survey [J] .Guangzhou Light Industry, 2008, 24 (10): 12-13.

[5] Shi Changsheng. Tai'an City, rural residents' health education and behavior intervention effect evaluation [J]. China Health Education, 2007, 23 (4): 289-311. 
[6] Li Liming, Rao Keqin, Kong Lingzhi, et al. Investigation on Nutrition and Health Status of Chinese Residents in 2002 [J]. Chinese Journal of Epidemiology, 2005, 26 (7): 478-484.

[7] Liu Yu, Gao Ersheng. Wu Junqing. Residents' knowledge, attitude, behavior and influencing factors analysis[J]. China Public Health, 2008, 24 (4): 482-485.

[8] Liang Hui, Ge Sheng, Ma Aiguo, and other elderly population nutrition status survey [J]. China Public Health, 2004; 20 (11): 1370

[9] Zhang Guiying, Wang Baogui, Zhao Linyi, and other elderly population nutrition status analysis[J]. Journal of Bethune Medical University, 2001; 27 (3): 323-4.

[10] Ge Guiyou, Chang Suying. Chinese residents' micronutrient intake[J]. Journal of Nutrition, 1999; 21 (3): 322-8.

[11] Huamei. Elderly nutrition and health care [J]. Chinese Journal of Clinical Healthcare, 2006; 9 (5): 527-8.

[12] Wu Kun. Nutrition and Food Hygiene (M). 5th edition. Beijing: People's Health Publishing House, 2003: 37. 